\title{
Wheeled mobility: Factors influencing mobility and assistive technology in veterans and servicemembers with major traumatic limb loss from Vietnam war and OIF/OEF conflicts
}

\author{
Justin Z. Laferrier, MSPT, OCS, SCS, CSCS, ATP $;^{1-3}$ Lynne V. McFarland, PhD; ${ }^{4-7}$ Michael L. Boninger, \\ MD; ${ }^{1-2,8-9}$ Rory A. Cooper, PhD; ${ }^{1-3,8-9 *}$ Gayle E. Reiber, PhD, MPH ${ }^{4-5}$ \\ ${ }^{1}$ Human Engineering Research Laboratories, Department of Veterans Affairs (VA) Rehabilitation Research and Devel- \\ opment Service, Pittsburgh, PA; ${ }^{2}$ VA Pittsburgh Healthcare System, Pittsburgh, PA; ${ }^{3}$ Department of Rehabilitation \\ Science and Technology, University of Pittsburgh, Pittsburgh, PA; ${ }^{4}$ Department of Health Services Research and Devel- \\ opment, VA Puget Sound Health Care System, Seattle,WA; Departments of ${ }^{5}$ Health Services, ${ }^{6}$ Epidemiology, and \\ ${ }^{7}$ Medicinal Chemistry, University of Washington, Seattle, WA; ${ }^{8}$ Department of Physical Medicine and Rehabilitation \\ and ${ }^{9}$ Department of Bioengineering, University of Pittsburgh, Pittsburgh, PA
}

\begin{abstract}
Returning wounded veterans and servicemembers to their highest level of function following traumatic injury is a priority of the Departments of Defense and Veterans Affairs. We surveyed 245 veterans from the Vietnam war and 226 servicemembers and veterans from Operation Iraqi Freedom/ Operation Enduring Freedom (OIF/OEF) conflicts with at least one major traumatic lower-limb loss to determine their use of mobility assistive technology (AT) and patterns of limb abandonment. Prosthetic device use without wheelchair use is found in $50.5 \%$ of Vietnam and $42.8 \%$ of OIF/OEF groups. Prostheses and supplementary wheelchairs are used by Vietnam (32\%) and OIF/OEF (53\%) groups $(p<0.01)$. Exclusive wheelchair use is more frequent in the Vietnam group (18\%) than in the OIF/OEF group $(4.0 \%, p<0.01)$. In Vietnam participants, multivariate analysis found that multiple-limb loss (adjusted odds ratio $[\mathrm{AOR}]=14.5 ;$ 95\% confidence interval [CI] 5.5-38.5), bilateral lower-limb loss (AOR $=12.7 ; 95 \%$ CI 6.2-26.1), and number of comorbidities (AOR $=1.3$; 95\% CI 1.2-1.5) are associated with increased likelihood of wheelchair use. In OIF/OEF participants, bilateral lower-limb loss (AOR = 29.8; 95\% CI 11.0-80.7), multiple-limb loss (AOR = 16.3; 95\% CI 3.1-85.3), cumulative trauma disorder $($ AOR $=2.4$; $95 \%$ CI 1.2-4.9), and number of combat injuries $(\mathrm{AOR}=1.4$;
\end{abstract}

95\% CI 1.2-1.7) are associated with wheelchair use. Combined use of different types of mobility ATs promotes improved rehabilitation and ability to function.

Key words: combat operations, mobility, mobility assistive technology, OIF/OEF, prosthetic device, rehabilitation, traumatic amputation, Vietnam, wheelchair, wounded servicemember.

\footnotetext{
Abbreviations: $\mathrm{AOR}=$ adjusted odds ratio, $\mathrm{AT}=$ assistive technology, $\mathrm{CI}=$ confidence interval, $\mathrm{DOD}=$ Department of Defense, $\mathrm{OEF}=$ Operation Enduring Freedom, OIF = Operation Iraqi Freedom, PTSD = posttraumatic stress disorder, $\mathrm{TBI}=$ traumatic brain injury, VA = Department of Veterans Affairs.

* Address all correspondence to Rory A. Cooper, PhD; VA Pittsburgh Healthcare System, Human Engineering Research Laboratories, 7108 Highland Dr, Bldg 4, Pittsburgh, PA 15206-1206; 412-365-4850; fax: 412-954-5340. Email: rcooper@pitt.edu

DOI:10.1682/JRRD.2009.03.0022
} 
JRRD, Volume 47, Number 4, 2010

\section{INTRODUCTION}

Traumatic injuries such as amputations, spinal cord injuries, burns, and multiple orthopedic and neurological disorders occur in combat operations [1-2]. Many of these injuries result from high concussive force blasts due to improvised explosive devices. Advances in early combat medical care and improvements in vehicle and personal armor are increasing survival rates, leading to increasing numbers of veterans and servicemembers living with a variety of severely disabling conditions [1-4].

The Department of Defense (DOD) instituted a recent rehabilitation directive aiming to return servicemembers with major traumatic amputations from Operation Iraqi Freedom (OIF) in Iraq and Operation Enduring Freedom (OEF) in Afghanistan to their highest possible functional level so that major limb loss does not prevent them from maximizing their career options in the military or civilian sectors [4-6]. To this aim, the Armed Forces Amputee Patient Care Programs at Walter Reed Army Medical Center, Brooke Army Medical Center, and Naval Medical Center San Diego deliver high-intensity, multidisciplinary rehabilitation combined with the latest assistive technology (AT) designed to return servicemembers with lower-limb amputations to their highest possible level of function [7].

Because of the physical impairment and decreased functional capacity, resulting from limb loss, as well as possible concomitant injuries, wounded servicemembers and veterans may use a wide variety of mobility AT. Mobility ATs include all technologies used to facilitate independent mobility (prosthetic devices, wheelchairs, or assistive devices). Mobility ATs are designed to increase the users' functional capacity and mobility and their access to the world. However, mobility ATs are frequently underused or discontinued, with abandonment rates as high as 30 percent [8]. The economic loss related to mobility AT abandonment and the possible long-term negative effects of inappropriate initial prescription motivated researchers to investigate underlying factors for underuse and abandonment to lower abandonment rates and improve prescription practices, thereby improving function in veterans and servicemembers with limb loss. In addition, currently, 18 to 21 percent of the servicemembers with traumatic amputations from the conflicts in Iraq and Afghanistan are returning to full Active Duty [6], compared with prior conflicts during which approximately 2 to 7 percent returned to Active Duty [9-10].
How different mobility ATs can help servicemembers return to Active Duty is unknown. Currently, little evidence-based literature exists related to the prescription of AT in those with combat-associated lower-limb loss.

This article investigates the factors for mobility AT use and abandonment in Vietnam and OIF/OEF groups with major lower-limb loss. These two distinct groups were chosen because they represent patterns of prosthetic device use before and after DOD rehabilitation programs were significantly changed for servicemembers with limb loss [4].

\section{METHODS}

\section{Study Design}

This study is a cross-sectional descriptive survey of all OIF/OEF veterans and servicemembers with major limb loss (as of 2008) and a sample of Vietnam war veterans with major limb loss.

\section{Study Participants}

Participants in this study were veterans and servicemembers from the Vietnam war and OIF/OEF conflicts, with at least one major traumatic amputation (excludes digits only) associated with a combat-field injury. These two groups were chosen to reflect mobility AT use before and after major changes were instituted in DOD rehabilitation care for battlefield injuries involving limb loss. We surveyed veterans and servicemembers during 2007 and 2008 to determine their general medical history and current health issues; prosthetic use, replacement, and abandonment patterns; satisfaction with prostheses; and use of other assistive devices. A description of the detailed study methods is found in this issue [11] and in the national Survey for Prosthetic Use, Appendix 1 (available online only).

\section{Mobility Assistive Technologies}

Mobility AT includes the use of prosthetic devices, wheelchairs (electronic, manual, or electronic scooters), and assistive devices. Wheelchair use was grouped into sole use (no prostheses) or supplementary wheelchair use (with prostheses). Assistive devices include canes, crutches, walking canes with attached seats, and rolling walkers with knee support. Questions on mobility AT were asked as part of the Survey for Prosthetic Use (Appendix 1 available online only) [11]. This survey 
asked a broad range of questions on the number and types of prostheses ever received, currently used, rejected, or abandoned. Reasons for abandoning prostheses were also assessed. Wheelchair use and use of other mobility assistive devices were assessed. Survey questions on prostheses and assistive-device use and abandonment were adapted from the Houghton Scale [12]. Additional questions were asked of survey participants who had abandoned all prostheses and were using wheelchairs, including time until prostheses abandonment, reasons for abandonment, and years of wheelchair use. Questions on satisfaction with prostheses were adapted from the Prosthesis Evaluation Questionnaire and the Orthotics and Prosthetic Users' Survey [13-14]. Detailed analyses of the types of prosthetic-device use, rejection, and replacement patterns and the satisfaction with prosthesis and services are addressed in other articles in this issue [11,1517].

\section{Survey Measures}

We examined other factors that may be associated with the use of mobility ATs, including demographic characteristics, comorbidities, quality of life, health status, combat-associated injuries, ambulatory function, and level of limb loss. Data on comorbidities included the presence of arthritis, depression, posttraumatic stress disorder (PTSD), traumatic brain injury (TBI), phantom pain, residual-limb pain, chronic back pain, migraines, and stroke. Types of combat-associated injuries were also assessed and are described in detail by Epstein et al. in this issue [18]. Self-rated quality of life and self-rated health status were rated as "excellent," "very good," "good," "fair," or "poor." Cumulative trauma disorder, or worn leg syndrome, included arthritis, joint pain, heel pain, or plantar fasciitis on the contralateral limb. The number of surgeries before and after the initial amputation was assessed. The survey collected data on seven graded levels of mobility function. For our article, we grouped mobility function into three levels: (1) nonambulatory (cannot walk), (2) ambulatory (household and community walkers), and (3) highly active (low- to highimpact recreational activities). The original survey collected data on 14 different levels of limb loss from shoulder to partial foot amputations. Here, we focus on three different groups of lower-limb loss: unilateral lower limb, bilateral lower limb, and multiple limbs, including at least one lower limb ( \pm upper limbs). For those with bilateral lower- and other multiple-limb loss, each limb was analyzed separately, because each limb may have different prosthetic-device rejection and use patterns. We excluded upper-limb loss levels (unilateral upper-limb and bilateral upper-limb loss).

\section{Statistical Analyses}

To describe univariate, bivariate, and multivariate findings, we analyzed the survey data using Stata 9.2 (StataCorp; College Station, Texas). For univariate analyses, statistical significance is based on Chi-square (categorical data), Mann-Whitney $U$ test (ordinal data), Student $t$-test (continuous data), and Fisher exact test, if cell size was $<5$. The level of significance is for a twosided $p<0.05$. Variables significant in univariate analyses are tested in logistic regression multivariate models. The outcome for the model is a bivariate outcome predicting any wheelchair use (sole or supplementary) compared with no current use of wheelchairs. To avoid overfitting the model, we added variables significant in univariate analyses using forward stepwise selection based on the log likelihood ratio and significance of the coefficient. We compared the new model with the previous model using the log likelihood ratio Chi-square test and kept the variable in the model if $p<0.05$. The variable was removed from the model if $p>0.05$ and if it was not a confounding factor. We also assessed potential interactions using the log likelihood ratio. Goodness of fit of the final model is assessed with the Hosmer-Lemeshow test statistic. A value of $p>0.05$ indicates a well-fitted model [19-20].

\section{RESULTS}

\section{Vietnam and OIF/OEF Groups}

Of the 245 participants from the Vietnam group, data on mobility AT use and abandonment were collected from 178 participants with unilateral lower-limb loss, 50 with bilateral lower-limb loss (100 limbs), and 17 with multiple-limb loss (including at least one lower limb [41 limbs]), for a total of 319 limbs. The multiple-limb-loss group in the Vietnam group includes three subgroups: (1) loss of one upper and one lower limb (total 20 limbs), (2) loss of two upper limbs and one lower limb (total 6 limbs), and (3) loss of one upper and two lower limbs (total 15 limbs).

Of the 226 participants from the OIF/OEF group, 172 participants had unilateral lower-limb loss, 42 had 
bilateral limb loss (84 limbs), and 12 had multiplelimb loss (31 limbs), for a total of 287 limbs. The multiplelimb-loss participants from the OIF/OEF group includes three subgroups: (1) loss of one upper and one lower limb (total 10 limbs), (2) loss of two upper limbs and one lower limb (total 6 limbs), and (3) loss of one upper and two lower limbs (total 15 limbs).

The Vietnam group was 100 percent male; the OIF/ OEF group was 98 percent male. The mean age of the Vietnam group with lower-limb loss was significantly older than the OIF/OEF group: $60.7 \pm 2.9$ and $29.0 \pm 5.6$, respectively, $p<0.001$. (Values are expressed as mean \pm standard deviation, unless otherwise stated.) Mean age and race are not significantly different in the three lowerlimb groups within conflict groups (data not shown). A description of other differences (comorbidities, combat injuries, quality of life, and types of prosthetic devices) is found in other articles in this issue [11,16-18].

\section{Prosthetic Device Use}

Current prosthetic device use with or without wheelchair use is common in all three lower-limb loss groups (Table 1). Of those who ever received any prostheses, current use of prosthetic devices (with or without wheelchair use) is highest in the unilateral lower-limb loss group for both the Vietnam (84\%) and OIF/OEF (96\%) participants. Fewer of the Vietnam war participants (67\%) with bilateral lower-limb loss currently use prostheses compared with OIF/OEF participants (95\%) $(p<$ 0.001 ). Current use of prostheses is similar for Vietnam and OIF/OEF groups with other lower multiple-limb loss (92\% and 90\%, respectively). Exclusive use of prosthetic devices (without wheelchair use) is similar for the Vietnam and OIF/OEF groups (50.5\% and $42.8 \%$, respectively).

\section{Wheelchair Use}

Sole or supplementary wheelchair use is common in both conflict groups: 50 percent of the Vietnam and 57 percent of the OIF/OEF participants use wheelchairs. Wheelchair use is highest in those with bilateral lowerlimb loss in Vietnam (80\%) and OIF/OEF (90\%, $p=$ $0.05)$ groups. Wheelchair use is also high in those with multiple-limb loss for both the Vietnam (71\%) and OIF/ OEF (77\%) groups. For those with unilateral lower-limb loss, wheelchairs are used less frequently in the Vietnam (28\%) than the OIF/OEF (37\%, $p=0.04$ ) group.

We also examined how prosthetic devices and wheelchairs are used in combination (Table 1). Supplementary wheelchair use with prostheses occurs in 32 percent of the Vietnam and 53 percent of the OIF/OEF participants $(p<0.001)$. In contrast, fewer used wheelchairs exclusively: 18 percent of Vietnam and 4 percent of OIF/OEF participants $(p<0.001)$. In both conflict groups, the principle mobility AT depends on the type of limb loss. For unilateral lower-limb loss, prostheses without wheelchair use are the principle mobility ATs for 72 percent of the Vietnam and 63 percent of the OIF/OEF group (data not shown). In contrast, the most frequent mobility AT use for bilateral lower and multiple-limb loss groups is a combination of prosthetic devices and supplementary wheelchair use. Supplementary chair use is significantly higher in bilateral lower-limb participants in the OIF/ OEF group $(83 \%, p=0.006)$ compared with the Vietnam group (46\%) (Table 1). A trend exists for supplementary wheelchair use to be higher in the OIF/OEF group (77\%) with multiple-limb loss compared with the Vietnam group ( $56 \%, p=0.09$ ).

Infrequently, wounded veterans and servicemembers do not receive any prostheses, transitioning instead directly into wheelchairs after rehabilitation for their mobility (Table 1). This transition is infrequent in both the Vietnam (5.0\%) and OIF/OEF (1.8\%) groups, and most (75\%) were at the transfemoral level (data not shown).

\section{Abandonment of Prostheses}

While most survey participants continue using prostheses, some completely discontinue all lower-limb prostheses because of a variety of reasons (pain, dissatisfaction, comorbidities, etc.) [17]. Abandonment of all prosthetic devices is significantly more frequent in the Vietnam participants (17\%) compared with OIF/OEF participants $(5 \%, p<0.001)$. Abandonment is highest (Table 1) in the Vietnam bilateral lower-limb loss group (33\%) and is significantly lower in the OIF/OEF group with bilateral limb loss $(5 \%, p=0.001)$. Both conflict groups with multiple-limb loss report low abandonment frequency $(7 \%-$ $10 \%)$ of prostheses. In the Vietnam group, the types of abandoned prostheses were mostly mechanical devices (mean number abandoned: $1.6 \pm 1.5$ unilateral lowerlimb loss, $2.0 \pm 1.3$ bilateral lower-limb loss, and $1.2 \pm$ 1.3 multiple-limb loss). Few of the abandoned prostheses in the Vietnam group were advanced (microprocessor) types: mean of $1 \pm 0$ for bilateral lower limb and mean of 0 for unilateral lower or multiple-limb loss. In the OIF/ OEF group, more of the abandoned prostheses were also mechanical (mean $3.5 \pm 4.3$ for unilateral lower, $1 \pm 0$ for 
Table 1.

Use of mobility assistive technology (AT) (prosthetic devices and wheelchairs) by number and percentage (\%) in Vietnam and Operation Iraqi Freedom/Operation Enduring Freedom (OIF/OEF) groups with major traumatic lower-limb loss by involved limb.

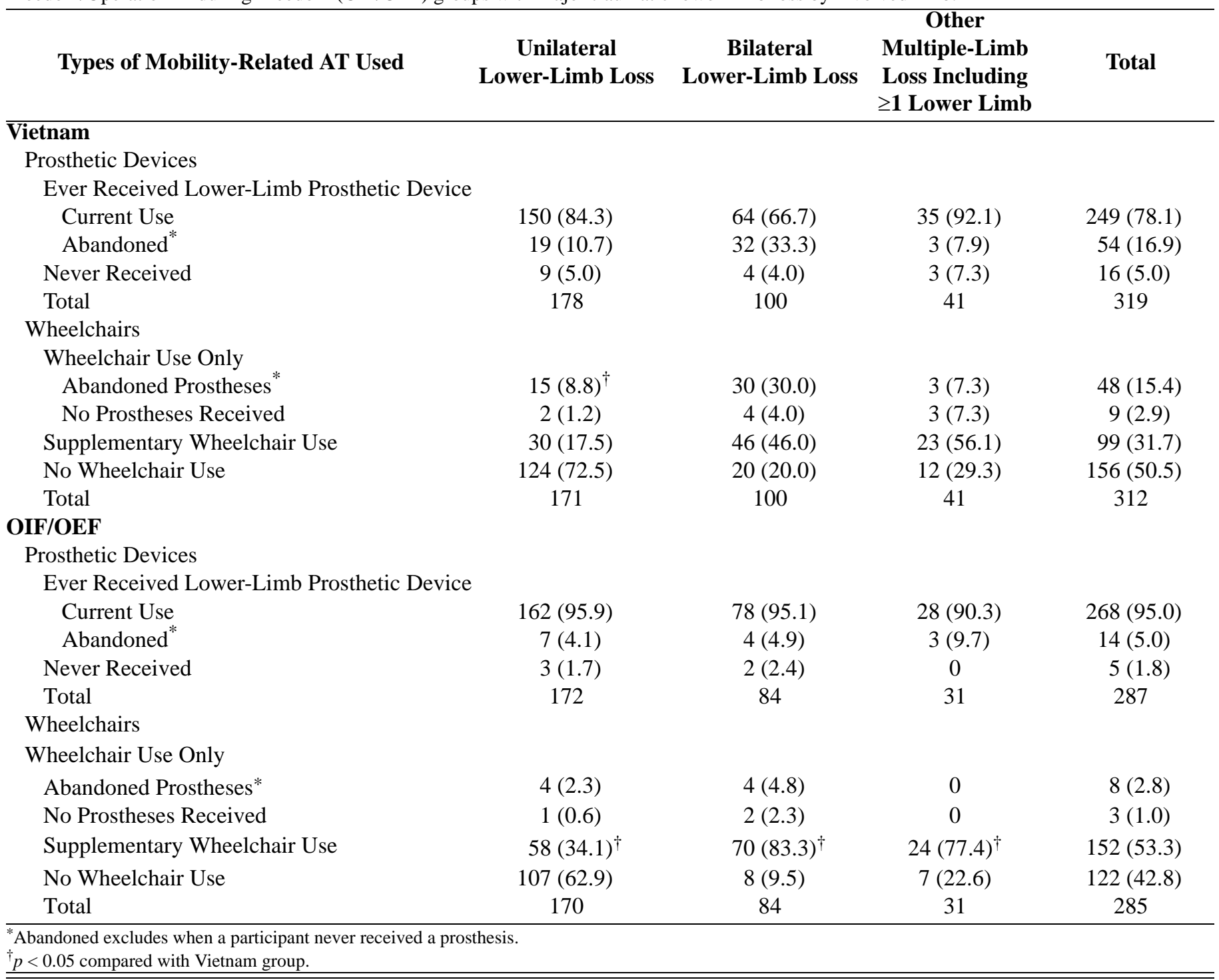

bilateral lower, and $0.6 \pm 0.8$ for multiple-limb loss). The OIF/OEF group abandoned fewer of the advanced devices (mean devices: $1.2 \pm 0.5$ for unilateral lower limbs, $1.5 \pm 0.3$ for bilateral lower limbs, and 0 for multiple-limb loss). The type of abandoned prosthetic device was not significantly different by conflict group, type, or level of limb loss (data not shown). The total number of prostheses ever received was significantly lower for those who abandoned all prostheses. Participants who abandoned all prostheses received an average total of four prostheses (both Vietnam and OIF/OEF participants) compared with an average of $12.9 \pm 10.5$ devices for Vietnam $(p<0.001)$ and $8.4 \pm 6.4$ devices for OIF/ OEF $(p<0.01)$ participants who continued to use prosthetic devices.

In both conflict groups, of those abandoning prostheses, most subsequently used wheelchairs exclusively. The level of limb loss is also important in predicting who may abandon prostheses (Table 2). Of those who currently used wheelchairs, most of those who abandoned prostheses had transfemoral limb loss. The highest frequency of abandonment occurred in those with bilateral transfemoral limb loss $(93 \%, p=0.008)$ in the Vietnam group. Abandonment in the OIF/OEF group was not significantly 
Table 2.

Comparison of level of major traumatic lower-limb loss by number and percentage (\%) among wheelchair users who abandoned prosthetic devices in Vietnam and Operation Iraqi Freedom/Operation Enduring Freedom (OIF/OEF) groups.

\begin{tabular}{|c|c|c|c|}
\hline $\begin{array}{c}\text { Lower-Limb } \\
\text { Amputation Level }\end{array}$ & $\begin{array}{c}\text { Unilateral } \\
\text { Lower-Limb Loss }\end{array}$ & $\begin{array}{c}\text { Bilateral } \\
\text { Lower-Limb Loss }\end{array}$ & $\begin{array}{l}\text { Other Multiple-Limb Loss } \\
\text { Including } \geq 1 \text { Lower Limb }\end{array}$ \\
\hline \multicolumn{4}{|l|}{ Vietnam } \\
\hline Transfemoral & 8 (57.1) & $28(93.3)^{*}$ & $1(50)$ \\
\hline Knee & $1(7.1)$ & $1(3.3)$ & 0 \\
\hline Transtibial & 0 & $1(3.3)$ & 0 \\
\hline \multicolumn{4}{|l|}{ OIF/OEF } \\
\hline Hip & $2(50.0)$ & 0 & 0 \\
\hline Transfemoral & $1(25.0)$ & $4(100)$ & 0 \\
\hline Transtibial & $1(25.0)$ & 0 & 0 \\
\hline Total Limbs & 4 & 4 & 0 \\
\hline
\end{tabular}

different by level of limb loss, but this finding may be due to this group's short time since limb loss. For those abandoning prostheses in favor of wheelchairs in the Vietnam group, 65 percent were manual wheelchairs, 26 percent were electric chairs, and 9 percent are electric scooters (data not shown). Most of the OIF/OEF group use a manual chairs $(88 \%)$ or electric scooters $(12 \%)$ after abandoning prostheses.

The mean time until abandonment of all prosthetic devices were assessed in the three limb-loss groups with each conflict group. Abandonment times are significantly different by type of limb loss (Figure). However, abandonment patterns may change as the OIF/OEF group ages to reflect the Vietnam group patterns. When similar time periods are compared (1-3 years postamputation), the Vietnam group still used their devices significantly longer (1.7 years) before abandonment compared with the OIF/ OEF group (0.6 years). For those with unilateral lowerlimb loss, Vietnam war veterans used prosthetic devices for an average of $13.9 \pm 13.7$ years before discontinuing them, whereas the OIF/OEF participants abandoned them after only $0.6 \pm 0.4$ years, $p<0.001$. For those with bilateral lower-limb loss, both conflict groups abandoned prosthetic devices more rapidly than those with unilateral lower-limb loss. The Vietnam group used lower-limb prosthetic devices longer on both limbs before abandoning them (6.7 \pm 8.6 years) compared with the OIF/OEF group $(0.3 \pm$ 0.3 years, $p<0.001$ ). For those with multiple-limb loss, prostheses were abandoned within the first year for both the Vietnam and OIF/OEF groups.

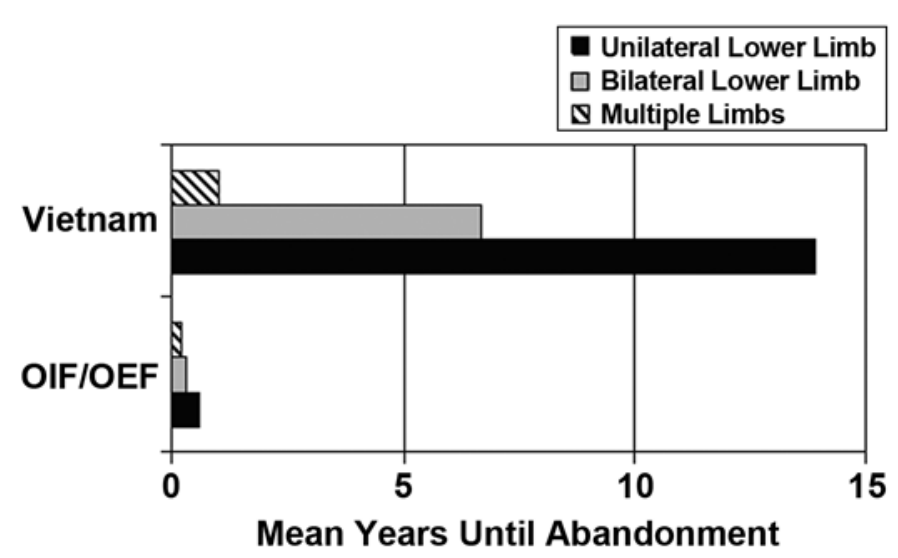

Figure.

Mean years of prosthetic device use until prosthetic device abandonment by Vietnam and Operation Iraqi Freedom/Operation Enduring Freedom (OIF/OEF) groups for three types of limb loss.

The principle reasons prostheses were abandoned in favor of wheelchair use are also examined (Table 3). In the Vietnam group with unilateral lower-limb loss, 42 percent abandoned prostheses because of cumulative trauma disorder. In contrast, the most frequent reason in the OIF/OEF group with unilateral lower-limb loss was combat injuries to the nonamputated lower limb (50\%). For those with bilateral lower-limb loss, the most common reasons in the Vietnam group were short length of the residual limb (33\%) and pain (25\%). However, in the OIF/OEF group with bilateral lower-limb loss, the reasons were too much fuss (50\%) or needing arms for daily 
Table 3.

Principle reason by number and percentage (\%) for prosthetic device abandonment among wheelchair users in Vietnam and Operation Iraqi Freedom/Operation Enduring Freedom (OIF/OEF) groups with major traumatic lower-limb loss by involved limb.

\begin{tabular}{|c|c|c|c|c|}
\hline $\begin{array}{c}\text { Principle Reason for } \\
\text { Lower-Limb Abandonment }\end{array}$ & $\begin{array}{c}\text { Unilateral } \\
\text { Lower-Limb Loss }\end{array}$ & $\begin{array}{c}\text { Bilateral } \\
\text { Lower-Limb Loss }\end{array}$ & $\begin{array}{l}\text { Other Multiple-Limb } \\
\text { Loss Including } \geq \mathbf{1} \\
\text { Lower Limb }\end{array}$ & Total \\
\hline \multicolumn{5}{|l|}{ Vietnam } \\
\hline Pain & $1(8.3)$ & $6(25.0)$ & 0 & $7(18.0)$ \\
\hline Too Much Fuss & $1(8.3)$ & $4(16.7)$ & 0 & $5(12.8)$ \\
\hline Need Arms & 0 & 0 & $3(100)$ & $3(7.7)$ \\
\hline Paralysis & $1(8.3)$ & 0 & 0 & $1(2.6)$ \\
\hline Residual Limbs Too Short & $1(8.3)$ & $8(33.3)$ & 0 & $9(23.1)$ \\
\hline Weight Gain & 0 & $2(8.3)$ & 0 & $2(5.1)$ \\
\hline Total & $12^{*}$ & $24^{*}$ & 3 & 39 (100) \\
\hline Cumulative Trauma Disorder & $1(25)$ & 0 & 0 & $3(37.5)$ \\
\hline Combat Injury-Other Limb & $2(50)$ & 0 & 0 & $2(25.0)$ \\
\hline Need Arms & 0 & $2(50)$ & 0 & $2(25.0)$ \\
\hline Total & 4 & 4 & 0 & $8(100)$ \\
\hline
\end{tabular}

activities (50\%). For those with multiple-limb loss, needing arms (100\% of Vietnam group) was the most common reason for prosthetic device abandonment.

\section{Assistive Devices}

Assistive devices, especially canes and crutches, were used less often than prosthetic devices or wheelchairs by the Vietnam and OIF/OEF groups with lowerlimb loss; however, they are still considered important mobility aids (Table 4). Crutches were used in 41.6 percent of those with unilateral lower-limb loss in the Vietnam group and 49.4 percent of the OIF/OEF group. Canes were used most frequently by the OIF/OEF group with bilateral limb loss (54.8\%) but were less frequently used by the Vietnam group (27\%). In those with multiplelimb loss, canes were most frequently used (35.3\%) in the OIF/OEF group and less so (13.6\%) in the Vietnam group.

\section{Multivariate Analysis for Wheelchair Use}

We analyzed factors associated with either sole or supplementary wheelchair use using logistic regression analysis for each conflict group separately (Table 5). In the Vietnam group, three factors significantly increased the likelihood of wheelchair use: multiple-limb loss (adjusted odds ratio $[\mathrm{AOR}]=14.5 ; 95 \%$ confidence interval [CI] 5.4, 38.4), bilateral lower-limb loss (AOR = 12.7; 95\% CI 6.2, 26.1), and an increasing number of comorbidities (AOR = 1.3; 95\% CI 1.1, 1.5). Two factors were significantly associated with less likely use of wheelchairs: ambulatory (AOR $=0.05 ; 95 \%$ CI 0.01, 0.24) and highly active (AOR $=0.02 ; 95 \%$ CI $0.01,0.12)$. In the OIF/OEF group, four factors significantly increased the likelihood of wheelchair use: bilateral lower-limb loss (AOR = 29.7; 95\% CI 11.0, 80.7), multiple-limb loss (AOR = 16.3; 95\% CI 3.1, 85.3), cumulative trauma disorder to the contralateral lower limb (AOR $=2.4$; 95\% CI $1.2,4.9)$, and the number of combat-associated injuries received $(\mathrm{AOR}=1.4 ; 95 \%$ CI 1.1, 1.6). No significant interaction terms were found in either model, and other factors analyzed were not significant including age, sex, race, weight gain, pain (residual limb, back), mental health conditions (depression), quality of life, prosthetic device satisfaction and fit, health status, stroke, PTSD, TBI, phantom limb sensation, number of postlimb-loss surgeries, or type of prosthetic device used. 
JRRD, Volume 47, Number 4, 2010

Table 4.

Comparison of mobility assistive devices by number and percentage (\%) used by Vietnam and Operation Iraqi Freedom/Operation Enduring Freedom (OIF/OEF) groups with major traumatic lower-limb loss by involved limb.

\begin{tabular}{|c|c|c|c|}
\hline $\begin{array}{l}\text { Types of Mobility } \\
\text { Assistive Devices Used }\end{array}$ & $\begin{array}{c}\text { Unilateral } \\
\text { Lower-Limb Loss }\end{array}$ & $\begin{array}{c}\text { Bilateral } \\
\text { Lower-Limb Loss }\end{array}$ & $\begin{array}{l}\text { Other Multiple-Limb } \\
\text { Loss Including } \geq 1 \\
\text { Lower Limb }\end{array}$ \\
\hline
\end{tabular}

\begin{tabular}{|c|c|c|c|c|}
\hline \multicolumn{5}{|l|}{ Vietnam } \\
\hline Crutches & $74(41.6)$ & $16(16.0)$ & $2(9.1)$ & $92(30.7)$ \\
\hline Cane & $58(32.6)$ & $27(27.0)$ & $3(13.6)$ & $88(29.3)$ \\
\hline Walker & $6(3.4)$ & 0 & 0 & $6(2.0)$ \\
\hline Cane with Seat & 0 & 0 & 0 & 0 \\
\hline Rolling Walker with Knee Support & $1(0.6)$ & 0 & 0 & $1(0.3)$ \\
\hline Self-Balancing Electric Vehicle & 0 & 0 & 0 & 0 \\
\hline Total $^{*}$ & 178 & 100 & 22 & 300 \\
\hline \multicolumn{5}{|l|}{ OIF/OEF } \\
\hline Crutches & $85(49.4)$ & $17(20.2)$ & $1(5.9)$ & $103(36.7)$ \\
\hline Cane & $44(25.6)$ & $46(54.8)^{\dagger}$ & $6(35.3)$ & $96(34.2)$ \\
\hline Walker & $12(7.0)$ & $3(3.6)$ & $1(5.9)$ & $16(5.7)$ \\
\hline Cane with Seat & $3(1.7)$ & 0 & 0 & $3(1.1)$ \\
\hline Rolling Walker with Knee Support & $1(0.6)$ & 0 & 0 & $1(0.3)$ \\
\hline Self-Balancing Electric Vehicle & $6(3.5)$ & $2(2.3)$ & 0 & $8(2.8)$ \\
\hline Total & 172 & 84 & 17 & 281 \\
\hline
\end{tabular}

Table 5.

Multivariate analysis of wheelchair use in Vietnam and Operation Iraqi Freedom/Operation Enduring Freedom (OIF/OEF) groups with combatassociated major lower-limb loss.

\begin{tabular}{lccc}
\hline \multicolumn{1}{c}{ Variable } & AOR & 95\% CI & p-Value \\
\hline Vietnam $^{*}$ & & & $<0.001$ \\
Multiple-Limb Loss $^{\dagger}$ & 14.48 & $5.46-38.46$ & $<0.001$ \\
Bilateral Lower-Limb Loss $^{\dagger}$ & 12.72 & $6.21-26.10$ & $<0.001$ \\
Number of Comorbidities & 1.29 & $1.15-1.46$ & $<0.001$ \\
Ambulatory & 0.05 & $0.01-0.24$ & $<0.001$ \\
Highly Active & 0.02 & $0.01-0.12$ & $<0.001$ \\
OIF/OEF $^{\ddagger}$ & & & $<0.001$ \\
Bilateral Lower-Limb Loss $^{\dagger}$ & 29.75 & $11.0-80.7$ & $<0.002$ \\
Multiple-Limb Loss & \\
Cumulative Trauma Disorder & 16.31 & $3.12-85.30$ & 0.001 \\
Total Number of Combat Injuries & 2.38 & $1.16-4.86$ & $1.15-1.65$ \\
\hline
\end{tabular}

${ }^{*}$ Goodness of fit for Vietnam model $\left(\chi^{2}=148, d f=67\right)$.

${ }^{\dagger}$ Compared with unilateral lower-limb loss.

${ }^{\ddagger}$ Goodness of fit for OIF/OEF model $\left(\chi^{2}=84.7, d f=26\right)$.

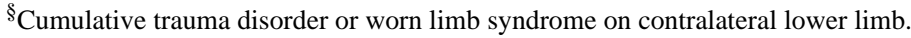

$\mathrm{AOR}=$ adjusted odds ratio, $\mathrm{CI}=$ confidence interval, $d f=$ degrees of freedom. 


\section{DISCUSSION}

Our survey shows different use of prosthetic devices, wheelchairs, and other ATs in two distinct groups of veterans and servicemembers with combat-associated lowerlimb loss. The Vietnam group's use of these devices was related to available technology at the time, attitudes about disability, and processes associated with aging. The OIF/ OEF group's use of these devices may have correlated with their younger ages, improvements in rehabilitation care and policies, shifts in attitudes about returning to Active Duty and more intense activities, availability of more technologically advanced devices, and their stages in the rehabilitation process.

Use of prosthetic devices, wheelchairs, and some assistive devices were significantly more common in the OIF/OEF group than in the Vietnam group. This finding is surprising, because one might expect more use of mobility ATs in older populations with more comorbidity and disability, such as Vietnam war veterans with lowerlimb loss. Mobility ATs may improve an individual's quality of life through increased functional capacity, independence, and participation in society. While mobility ATs successfully serve these purposes to varying degrees, some users are dissatisfied with their prostheses or assistive devices and, consequently, underuse or abandon them. In the Vietnam group, those with unilateral lowerlimb loss used their prosthetic devices for a sustained period of time before discontinuing them. Reasons for abandonment in this group were typically associated with the process of aging (device too heavy, comorbid conditions, vascular conditions) rather than dissatisfaction with the device itself. In contrast, those with unilateral lowerlimb loss in the OIF/OEF group, who were followed for an average of 3 years, discarded prosthetic devices within the first year because of dissatisfaction with the device or because of the combat injuries to the other leg. As this group ages, more abandonment may occur because of age-related conditions similar to the Vietnam group. The clinical literature is sparse on reasons for abandonment of prosthetic devices in combat-associated lower-limb loss. Additional research is needed on better prosthetic device fit, methods to decrease pain, and attention to innovations to increase satisfaction (decrease weight of the device or design more comfortable harnesses) with the devices to conserve prosthetic device use, thereby enhancing physical function as these servicemembers and veterans age.
Our study found that, while many rely on prostheses, wheelchair use is a frequent aid for mobility, especially for those with bilateral lower- or multiple-limb loss. The availability of a wheelchair for prosthetic device users is paramount, because the wheelchairs are often necessary to use as a backup when prostheses are repaired or replaced and during times when the residual limb cannot support the prostheses because of infections, soft-tissue injury, weight change, or poor socket fit. In addition, many of the survey participants reported that evening use of a wheelchair helps the residual limb rest after a day of using a prosthetic device use. This shift in acceptance of the wheelchair as an important mobility AT to a supplement for primary prosthetic use could explain the higher levels of supplementary wheelchair use among OIF/OEF servicemembers and veterans when compared with Vietnam war veterans. Nearly all wounded servicemembers with lower-limb loss were trained on the use of prostheses, but not as many received training on the other forms of mobility AT. A recent study from the University of Pittsburgh reported only 18 percent of wounded servicemembers reported receiving formal wheelchair training as part of their rehabilitation [21]. One possible explanation for this preference for prosthetic training over wheelchair training is the patient's desire to return to ambulation. Many people in the early months after a traumatic disability resist wheelchairs because they insist they will walk again. Other studies have found that training is paramount, because choosing the type of wheelchairs and assessing functional ability need individual attention to increase mobility safely [22-28]. Thus, we recommend that wounded servicemembers with lowerlimb loss be offered wheelchair training early in their rehabilitation process, regardless of their perceived future needs for a wheelchair or assistive device.

In our study, several factors are associated with wheelchair use: bilateral lower- or multiple-limb loss, cumulative trauma disorder, comorbidities, combat injuries, and a low ambulatory functional level. As wounded servicemembers and veterans age (as in the Vietnam group), the presence of decreased physical conditioning and chronic conditions such as diabetes and vascular diseases may increase the likelihood of wheelchair use. For the OIF/OEF participant, bilateral lower- and multiple-limb losses are associated with wheelchair use, but cumulative trauma disorder also significantly predicts wheelchair use. Because of improvements in combat-injury care and widespread use of body armor, more injured OIF/OEF servicemembers 
are surviving but with multiple-limb injuries, which may involve challenges for mobility $[3,29]$. Other studies in noncombat-associated lower-limb loss have found pain, poor prosthetic fit, poor prosthetic performance, comorbidities, change in cardiovascular fitness and activity level, change in prosthetic use, lack of consideration of the user's needs in the prescription process to increase the likelihood of wheelchair use [30-35].

One of the main focuses of the multidisciplinary team is to educate the individual on the possibility of success or failure in using prosthetic devices, based on their medical status, the severity of injury, the availability of resources, and the state of technology at the time. Collaborative efforts of the medical care team and the injured servicemember or veteran need to match the person's expectations and preferences within the environment of use, device function, and type of mobility AT [36-37]. Multiple types of mobility AT may also be useful, because of the number of issues associated with relying on one form of mobility AT. Increased forces sustained by the nonamputated limb (for example, in the case of someone with unilateral transfemoral limb loss using a prosthetic device for primary mobility) may lead to early onset arthritis. Similarly, an individual who only uses a wheelchair for mobility may be at a higher risk of developing a degenerative rotator cuff injury to the shoulder joint. Our study finds that many survey participants use more than one type of mobility AT, including prosthetic devices, supplementary use of wheelchairs, and various assistive devices such as canes, crutches, and walkers. A combined approach concerning mobility AT may help decrease the possible detrimental effects of the prolonged use of a sole form of mobility AT. Having an option of which mobility AT to use for different activities and fatigue levels could increase satisfaction and functional mobility, but this needs further study.

Our study of combat-associated limb loss responds to the call for AT outcomes research [38]. Although our population may be distinguished by the cause of the limb loss, studies of mobility ATs in other populations of lower-limb loss (spinal cord injury, stroke, or vascular disease) also report 43 to 50 percent use of mobility AT devices, mostly wheelchairs [39-41]. More research is needed to further understand why these mobility ATs are abandoned, who is best served by specific types of devices, and how to train all people with lower-limb loss to best use these valuable tools.

This information will be useful for developing improved guidelines for mobility AT prescription, addressing correctable issues leading to abandonment, and documenting for policy makers the importance and role of wheelchairs and other ATs to increase mobility in veterans and servicemembers with lower-limb loss.

\section{CONCLUSIONS}

The majority of the individuals from the Vietnam war and OIF/OEF conflicts with lower-limb loss choose to use a combination of mobility ATs for their means of mobility. Individuals sustaining multiple-limb loss, especially at proximal levels, tend to either abandon all prostheses in favor of a wheelchair for their primary means of mobility or choose to use both prostheses and a wheelchair. The availability of a variety of types of mobility ATs enhances physical functioning for veterans and servicemembers with lower-limb loss.

Until the OIF/OEF group reaches the same age and has similar life experiences as the Vietnam group, the influence of the recent DOD/Department of Veterans Affairs (VA) rehabilitation policies on prosthetic device and AT use may not be fully realized. However, the experiences of the Vietnam group may help predict future trends of prosthetic and assistive device use for these younger servicemembers as they age.

\section{ACKNOWLEDGMENTS}

\section{Author Contributions:}

Study concept and design: L. V. McFarland, G. E. Reiber.

Acquisition of data: L. V. McFarland, G. E. Reiber.

Analysis and interpretation of data: J. Z. Laferrier, L. V. McFarland, G. E. Reiber.

Drafting of manuscript: J. Z. Laferrier, L. V. McFarland, M. L. Boninger, R. A. Cooper, G. E. Reiber.

Critical revision of manuscript for important intellectual content: J. Z. Laferrier, L. V. McFarland, M. L. Boninger, R. A. Cooper, G. E. Reiber.

Obtained funding: L. V. McFarland, G. E. Reiber.

Administrative, technical, or material support: J. Z. Laferrier, L. V. McFarland, M. L. Boninger, R. A. Cooper, G. E. Reiber.

Study supervision: L. V. McFarland, G. E. Reiber.

Financial Disclosures: The authors have declared that no competing interests exist.

Funding/Support: This material was based on work supported by the VA, Health Services Research and Development Service, grant IIR 05244, and a Career Scientist Award to Dr. Reiber, grant RCS 98-353.

The views expressed in this article are those of the authors and do not necessarily reflect the position or policy of the VA or the DOD. 
Additional Contributions: A special thank you to all the Vietnam and OIF/OEF veterans and servicemembers who participated in our survey. We would like to thank Jane Emens and Koriann Brousseau for administrative support on this project.

Institutional Review: We received human subjects approval from the University of Washington, Seattle, Washington; VA Puget Sound Health Care System, Seattle, Washington; and Madigan Army Medical Center, Tacoma, Washington.

Participant Follow-Up: The authors plan to inform participants of the publication of this study.

\section{REFERENCES}

1. Owens BD, Kragh JF Jr, Macaitis J, Svoboda SJ, Wenke JC. Characterization of extremity wounds in Operation Iraqi Freedom and Operation Enduring Freedom. J Orthop Trauma. 2007;21(4):254-57. [PMID: 17414553] DOI:10.1097/BOT.0b013e31802f78fb

2. Zouris JM, Wade AL, Magno CP. Injury and illness casualty distributions among U.S. Army and Marine Corps personnel during Operation Iraqi Freedom. Mil Med. 2008;173(3): 247-52. [PMID: 18419026]

3. Eastridge BJ, Jenkins D, Flaherty S, Schiller H, Holcomb JB. Trauma system development in a theater of war: Experiences from Operation Iraqi Freedom and Operation Enduring Freedom. J Trauma. 2006;61(6):1366-73.

[PMID: 17159678]

DOI:10.1097/01.ta.0000245894.78941.90

4. Pasquina PF. Optimizing care for combat amputees: Experiences at Walter Reed Army Medical Center. J Rehabil Res Dev. 2004;41(3B):vii-xii. [PMID: 15543454]

DOI:10.1682/JRRD.2004.05.0051

5. Kerkovich DM. Recent QUERI workshop analyzes optimum treatment for combat amputees. J Rehabil Res Dev. 2004;41(4):xi-xii. [PMID: 15558379]

DOI:10.1682/JRRD.2004.04.0000

6. Scoville C. Congressional testimony: Amputee care, July 22, 2004. House Committee on Veterans' Affairs. 2004.

7. Gajewski D, Granville R. The United States Armed Forces Amputee Patient Care Program. J Am Acad Orthop Surg. 2006;14(10 Spec No.):S183-87. [PMID: 17003196]

8. Phillips B, Zhao H. Predictors of assistive technology abandonment. Assist Technol. 1993;5(1):36-45. [PMID: 10171664]

9. Kishbaugh D, Dillingham TR, Howard RS, Sinnott MW, Belandres PV. Amputee soldiers and their return to active duty. Mil Med. 1995;160(2):82-84. [PMID: 7783923]

10. Dillingham TR, Braverman SE, Belandres PV. Persian Gulf War amputees: Injuries and rehabilitative needs. Mil Med. 1994;159(10):635-39. [PMID: 7870319]

11. Reiber GE, McFarland LV, Hubbard S, Maynard C, Blough DK, Gambel JM, Smith DG. Servicemembers and veterans with major traumatic limb loss from Vietnam war and OIF/ OEF conflicts: Survey methods, participants, and summary findings. J Rehabil Res Dev. 2010;47(4):275-98.

12. Devlin M, Pauley T, Head K, Garfinkel S. Houghton Scale of prosthetic use in people with lower-extremity amputations: Reliability, validity, and responsiveness to change. Arch Phys Med Rehabil. 2004;85(8):1339-44.

[PMID: 15295762]

DOI:10.1016/j.apmr.2003.09.025

13. Legro MW, Reiber GE, Smith DG, Del Aguila M, Larsen J, Boone D. Prosthesis Evaluation Questionnaire for persons with lower-limb amputations: Assessing prosthesis-related quality of life. Arch Phys Med Rehabil. 1998;79(8):931-38. [PMID: 9710165] DOI:10.1016/S0003-9993(98)90090-9

14. Heinemann AW, Bode RK, O'Reilly C. Development and measurement properties of the Orthotics and Prosthetics Users' Survey (OPUS): A comprehensive set of clinical outcome instruments. Prosthet Orthot Int. 2003;27(3):191-206. [PMID: 14727700] DOI:10.1080/03093640308726682

15. McFarland LV, Hubbard Winkler SL, Heinemann AW, Jones M, Esquenazi A. Unilateral upper-limb loss: Satisfaction and prosthetic-device use in veterans and servicemembers from Vietnam and OIF/OEF conflicts. J Rehabil Res Dev. 2010;47(4):299-316.

16. Dougherty PJ, McFarland LV, Smith DG, Esquenazi A, Blake DJ, Reiber GE. Multiple traumatic limb loss: A comparison of Vietnam veterans to OIF/OEF servicemembers. J Rehabil Res Dev. 2010;47(4):333-48.

17. Gailey R, McFarland LV, Cooper RA, Czerniecki J, Gambel JM, Hubbard S, Maynard C, Smith DG, Raya M, Reiber GE. Unilateral lower-limb loss: Prosthetic device use and functional outcomes in servicemembers from Vietnam war and OIF/OEF conflicts. J Rehabil Res Dev. 2010; 47(4):317-32.

18. Epstein RA, Heinemann AW, McFarland LV. Quality of life for veterans and servicemembers with major traumatic limb loss from Vietnam and OIF/OEF conflicts. J Rehabil Res Dev. 2010;47(4):373-86.

19. Colak C, Colak MC, Orman MN. [The comparison of logistic regression model selection methods for the prediction of coronary artery disease]. Anadolu Kardiyol Derg. 2007; 7(1):6-11. Turkish. [PMID: 17347067]

20. Ash AS. Evaluating the performance of risk-adjustment methods: Dichotomous measures. In: Iezzoni LI, editor. Risk adjustment for measuring health care outcomes. Ann Arbor (MI): Health Administration Press; 1994. p. 313-46.

21. Karmarkar AM, Collins DM, Wichman T, Franklin A, Fitzgerald SG, Dicianno BE, Pasquina PF, Cooper RA. Prostheses and wheelchair use in veterans with lower-limb amputation. J Rehabil Res Dev. 2009;46(5):567-76. 
JRRD, Volume 47, Number 4, 2010

[PMID: 19882491]

DOI:10.1682/JRRD.2008.08.0102

22. Batavia M, Batavia AI, Friedman R. Changing chairs: Anticipating problems in prescribing wheelchairs. Disabil Rehabil. 2001;23(12):539-48. [PMID: 11432651] DOI:10.1080/09638280010022531

23. Kittel A, Di MA, Stewart H. Factors influencing the decision to abandon manual wheelchairs for three individuals with a spinal cord injury. Disabil Rehabil. 2002;24(1-3): 106-14. [PMID: 11827144] DOI:10.1080/09638280110066785

24. Best KL, Kirby RL, Smith C, MacLeod DA. Wheelchair skills training for community-based manual wheelchair users: A randomized controlled trial. Arch Phys Med Rehabil. 2005;86(12):2316-23. [PMID: 16344029]

DOI:10.1016/j.apmr.2005.07.300

25. Coolen AL, Kirby RL, Landry J, MacPhee AH, Dupuis D, Smith C, Best KL, Mackenzie DE, MacLeod DA. Wheelchair skills training program for clinicians: A randomized controlled trial with occupational therapy students. Arch Phys Med Rehabil. 2004;85(7):1160-67. [PMID: 15241768] DOI:10.1016/j.apmr.2003.10.019

26. Cooper RA, Cooper R, Boninger ML. Trends and issues in wheelchair technologies. Assist Technol. 2008;20(2):61-72. [PMID: 18646429]

27. MacPhee AH, Kirby RL, Coolen AL, Smith C, MacLeod DA, Dupuis DJ. Wheelchair skills training program: A randomized clinical trial of wheelchair users undergoing initial rehabilitation. Arch Phys Med Rehabil. 2004;85(1):41-50. [PMID: 14970966] DOI:10.1016/S0003-9993(03)00364-2

28. WHO. New guidelines released on wheelchairs to support users in developing countries [Internet]. Geneva (Switzerland): World Health Organization (WHO), Disability and Rehabilitation Team (DAR); 2009 [cited 2009 May 7]. Available from: http://www.who.int/disabilities/publications/technology/wheelchairguidelines/en/index.html/.

29. Holcomb JB, McMullin NR, Pearse L, Caruso J, Wade CE, Oetjen-Gerdes L, Champion HR, Lawnick M, Farr W, Rodriguez S, Butler FK. Causes of death in U.S. Special Operations Forces in the global war on terrorism: 2001-2004. Ann Surg. 2007;245(6):986-91. [PMID: 17522526] DOI:10.1097/01.sla.0000259433.03754.98

30. Kurichi JE, Kwong PL, Reker DM, Bates BE, Marshall CR, Stineman MG. Clinical factors associated with prescription of a prosthetic limb in elderly veterans. J Am Geriatr Soc. 2007;55(6):900-6. [PMID: 17537091] DOI:10.1111/j.1532-5415.2007.01187.X

31. Kurichi JE, Stineman MG, Kwong PL, Bates BE, Reker DM. Assessing and using comorbidity measures in elderly veterans with lower extremity amputations. Gerontology.
2007;53(5):255-59. [PMID: 17435390]

DOI:10.1159/000101703

32. Sherman RA. Utilization of prostheses among US veterans with traumatic amputation: A pilot survey. J Rehabil Res Dev. 1999;36(2):100-108. [PMID: 10661526]

33. Bilodeau S, Hébert R, Desrosiers J. Lower limb prosthesis utilisation by elderly amputees. Prosthet Orthot Int. 2000; 24(2):126-32. [PMID: 11061199]

DOI:10.1080/03093640008726535

34. Dillingham TR, Pezzin LE, MacKenzie EJ, Burgess AR. Use and satisfaction with prosthetic devices among persons with trauma-related amputations: A long-term outcome study. Am J Phys Med Rehabil. 2001;80(8):563-71.

[PMID: 11475475] DOI:10.1097/00002060-200108000-00003

35. Gauthier-Gagnon C, Grise MC, Potvin D. Predisposing factors related to prosthetic use by people with a transtibial and transfemoral amputation. J Prosthet Orthot. 1998;10(4): 99-109. DOI:10.1097/00008526-199801040-00006

36. Scherer MJ, Sax C, Vanbiervliet A, Cushman LA, Scherer JV. Predictors of assistive technology use: The importance of personal and psychosocial factors. Disabil Rehabil. 2005;27(21):1321-31. [PMID: 16298935] DOI:10.1080/09638280500164800

37. Simpson RC, LoPresti EF, Cooper RA. How many people would benefit from a smart wheelchair? J Rehabil Res Dev. 2008;45(1):53-72. [PMID: 18566926]

DOI:10.1682/JRRD.2007.01.0015

38. Lenker JA, Scherer MJ, Fuhrer MJ, Jutai JW, DeRuyter F. Psychometric and administrative properties of measures used in assistive technology device outcomes research. Assist Technol. 2005;17(1):7-22. [PMID: 16121642]

39. Jutai J, Coulson S, Teasell R, Bayley M, Garland J, Mayo N, Wood-Dauphinee S. Mobility assistive device utilization in a prospective study of patients with first-ever stroke. Arch Phys Med Rehabil. 2007;88(10):1268-75. [PMID: 17908568] DOI:10.1016/j.apmr.2007.06.773

40. Gitlin LN, Schemm RL, Landsberg L, Burgh D. Factors predicting assistive device use in the home by older people following rehabilitation. J Aging Health. 1996;8(4):554-75. [PMID: 10182386] DOI:10.1177/089826439600800405

41. Hubbard SL, Fitzgerald SG, Reker DM, Boninger ML, Cooper RA, Kazis LE. Demographic characteristics of veterans who received wheelchairs and scooters from Veterans Health Administration. J Rehabil Res Dev. 2006;43(7): 831-44. [PMID: 17436170] DOI:10.1682/JRRD.2005.11.0174

Submitted for publication March 2, 2009. Accepted in revised form July 8, 2009. 